\title{
Orally active microtubule-targeting agent, MPTOB271, for the treatment of human non-small cell lung cancer, alone and in combination with erlotinib
}

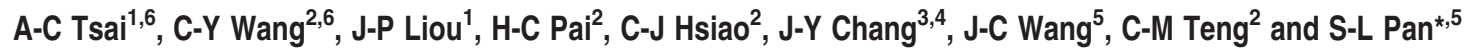

Microtubule-binding agents, such as taxanes and vinca alkaloids, are used in the treatment of cancer. The limitations of these treatments, such as resistance to therapy and the need for intravenous administration, have encouraged the development of new agents. MPTOB271 (N-[1-(4-Methoxy-benzenesulfonyl)-2,3-dihydro-1H-indol-7-yl]-1-oxy-isonicotinamide), an orally active microtubule-targeting agent, is a completely synthetic compound that possesses potent anticancer effects in vitro and in vivo. Tubulin polymerization assay and immunofluorescence experiment showed that MPTOB271 caused depolymerization of tubulin at both molecular and cellular levels. MPTOB271 reduced cell growth and viability at nanomolar concentrations in numerous cancer cell lines, including a multidrug-resistant cancer cell line NCI/ADR-RES. Further studies indicated that MPTOB271 is not a substrate of P-glycoprotein (P-gp), as determined by flow cytometric analysis of rhodamine-123 (Rh-123) dye efflux and the calcein acetoxymethyl ester (calcein AM) assay. MPT0B271 also caused G2/M cell-cycle arrest, accompanied by the up-regulation of cyclin B1, p-Thr161 Cdc2/p34, serine/threonine kinases polo-like kinase 1, aurora kinase A and B and the downregulation of Cdc25C and p-Tyr15 Cdc2/p34 protein levels. The appearance of MPM2 and the nuclear translocation of cyclin B1 denoted M phase arrest in MPTOB271-treated cells. Moreover, MPTOB271 induced cell apoptosis in a concentration-dependent manner; it also reduced the expression of Bcl-2, Bcl-xL, and Mcl-1 and increased the cleavage of caspase-3 and -7 and poly (ADP-ribose) polymerase (PARP). Finally, this study demonstrated that MPTOB271 in combination with erlotinib significantly inhibits the growth of the human non-small cell lung cancer A549 cells as compared with erlotinib treatment alone, both in vitro and in vivo. These findings identify MPTOB271 as a promising new tubulin-binding compound for the treatment of various cancers.

Cell Death and Disease (2014) 5, e1162; doi:10.1038/cddis.2014.128; published online 10 April 2014

Subject Category: Cancer

Microtubules are the main component of the cytoskeleton and have an essential role in cell division, intracellular transport, and motility. ${ }^{1}$ Several clinically important microtubule-targeting agents, such as taxanes and vinca alkaloids, bind to microtubules, thereby altering the normal dynamic equilibrium and resulting in either the stabilization or destabilization of microtubules. $^{2}$ The consequence of disrupting the microtubule organization with these drugs is the G2/M-phase arrest of the cell cycle and ultimately apoptotic or non-apoptotic cell death. $^{3,4}$

Even though microtubule-targeting agents are used clinically to treat patients with neoplastic disease, they have substantial drawbacks such as the development of resistance over time. ${ }^{5}$ Drug resistance can be intrinsic, in which case the first chemotherapy fails, or acquired, in which case there is a response to the first round of chemotherapy but failure of the second. ${ }^{6}$ In either case, tumors become refractory to various structurally different compounds. The most common form of drug resistance to taxanes and other microtubule-targeting agents is overexpression of the efflux pump P-glycoprotein (P-gp)/multidrug resistance (MDR) protein. ${ }^{7}$ Clinically used microtubule-targeting agents, such as paclitaxel and vinblastine, are substrates for $\mathrm{P}$-gp. Thus, a microtubule-targeting agent is required, which circumvents these mechanisms of drug resistance. Such a treatment could be advantageous for patients with drug-resistant tumors. ${ }^{8-10}$ Furthermore, another limitation of current treatments is their requirement for intravenous delivery, which leads to hypersensitivity reactions. ${ }^{11,12}$

Signal transducer and activator of transcription 3 (STAT3) is inappropriately activated in various tumor types, such as lymphoma, breast, ovarian, pancreatic, and lung cancer, and is particularly activated in aggressive and invasive tumors. ${ }^{13,14}$ STAT3 is a transcription factor that translocates

\footnotetext{
${ }^{1}$ School of Pharmacy, College of Pharmacy, Taipei Medical University, No. 250, Wu-hsing Street, Taipei 11031, Taiwan; ${ }^{2}$ Pharmacological Institute, College of Medicine, National Taiwan University, Taipei, Taiwan; ${ }^{3}$ National Institute of Cancer Research, National Health Research Institutes, Tainan, Taiwan; ${ }^{4}$ Division of Hematology and Oncology, Department of Internal Medicine, National Cheng Kung University Hospital, Tainan, Taiwan and ${ }^{5}$ The Ph.D. Program for Cancer Biology and Drug Discovery, College of Medical Science and Technology, Taipei Medical University, No. 250, Wu-hsing Street, Taipei 11031, Taiwan

*Corresponding author: S-L Pan, The Ph.D. Program for Cancer Biology and Drug Discovery, College of Medical Science and Technology, Taipei Medical University, No. 250, Wu-hsing Street, Taipei 11031, Taiwan. Tel: +886 227361661 ext 7671; Fax: +886 2 23221742; E-mail: slpan@tmu.edu.tw or psl0826@ms13.hinet.net

${ }^{6}$ These authors contributed equally to this work.

Keywords: non-small cell lung cancer; microtubule-binding agents; apoptosis; erlotinib

Abbreviations: P-gp, P-glycoprotein; Rh-123, rhodamine-123; calcein AM, calcein acetoxymethyl ester; PARP, poly (ADP-ribose) polymerase; MDR, multidrug resistance; MRP, multidrug resistance-associated protein; STAT3, signal transducer and activator of transcription 3; EGFR, epidermal growth factor receptor; NSCLC, non-small cell lung cancer; PLK1, serine/threonine kinases polo-like kinase 1; DAPI, 4,6-diamidino-2-phenylindole; PI, propidium iodide; siRNA, small interfering RNA Received 21.10.13; revised 15.2.14; accepted 28.2.14; Edited by G Ciliberto
} 
into the nucleus, binding to its responsive element after activation. STAT3 regulates the expression of various genes including $\mathrm{Bcl}-\mathrm{xL}, \mathrm{Mcl}-1$, cyclin $\mathrm{D} 1$, and $\mathrm{p53}$, which regulate cell-cycle progression, cell survival, and proliferation. ${ }^{15,16}$ In addition to its transcriptional function, STAT3 associates with the cytoskeleton and may thus regulate microtubule function. Microtubule-interfering agents, such as paclitaxel and vinorelbine, can inhibit STAT3 tyrosine phosphorylation. ${ }^{17,18}$

Epidermal growth factor receptor (EGFR), a transmembrane glycoprotein, is frequently overexpressed in human tumors such as breast, ovarian, prostate, pancreatic, and non-small cell lung cancer (NSCLC). This overexpression is correlated with poor prognosis and worse clinical outcome. Thus, targeted therapies directed at blocking EGFR function are attractive potential therapeutics for cancer. ${ }^{19}$ Erlotinib, a reversible EGFR tyrosine kinase inhibitor, was initially approved for treatment of patients with advanced NSCLC who had failed one chemotherapy regimen. Although clinical results have demonstrated that erlotinib monotherapy showed a survival benefit in comparison with gemcitabine for patients with NSCLC or pancreatic cancer, resistance to erlotinib reduces its efficacy. ${ }^{20,21}$ The T790M point mutation in EGFR causes a conformational change at the ATP binding pocket, thus decreasing the affinity between erlotinib and EGFR and leading to acquired/secondary resistance..$^{22,23}$

In the present study, we demonstrate that MPTOB271 (N-[1-(4-methoxy-benzenesulfonyl)-2,3-dihydro-1H-indol-7-yl]1-oxy-isonicotinamide), an orally active compound, represses microtubule polymerization. We evaluated the antiproliferative activity of MPTOB271 against several cancer cell lines as well as P-gp-overexpressing NCl/ADR-RES cells. We investigated the action mechanism of MPTOB271 on cell-cycle progression and apoptosis. Furthermore, we explored the anticancer activity of MPTOB271 alone and in combination with erlotinib in vitro and in vivo. Our results suggest that MPTOB271 is a promising therapeutic candidate for the treatment of human cancers.

\section{Results}

MPTOB271 inhibits tubulin polymerization. MPTOB271 (Figure 1a) inhibited microtubule formation in an in vitro tubulin polymerization assay, and the effect was similar to the inhibition induced by the microtubule-destabilizing agents colchicine and vincristine. In contrast, the widely used microtubule-stabilizing agent paclitaxel induced a marked increase in tubulin polymerization (Figure 1b). The effect of MPTOB271 on the arrangement and distribution of the microtubule network in cells was studied in situ by immunofluorescence. As shown in Figure 1c, treatment of A549 cells with MPTOB271 disrupted the microtubule cytoskeleton. These data indicate that MPTOB271 depolymerizes microtubules in tumor cells.

\footnotetext{
MPTOB271 is an orally bioavailable synthetic inhibitor of tumor growth in vivo. The MPTOB271 plasma concentration versus time profile following intravenous and oral administration to CD-1 $(\mathrm{Crl}$.) mice is shown in Figure $1 \mathrm{~d}$. The half-life $\left(t_{1 / 2}\right)$ for oral administration $(2.0 \mathrm{~h})$ was slightly longer than the half-life for intravenous administration with
}

the absolute oral bioavailability being $26 \%$. At an oral dose of $20 \mathrm{mg} / \mathrm{kg}$, MPTOB271 showed rapid absorption in mice with a short maximal plasma concentration time $\left(T_{\max }\right)$ of $15 \mathrm{~min}$ (the first sampling time point). The mean $C_{\max }$ and $\mathrm{AUC}_{(0-27)}$ of MPTOB271 was $402 \mathrm{mg} / \mathrm{ml}$ and $558 \mathrm{ng} \mathrm{h} / \mathrm{ml}$, respectively. To evaluate the effect of MPTOB271 in vivo, nude mice that received tumor xenografts of the human NSCLC cell line A549 were used. As illustrated in Figure 1e (upper panel), oral administration of MPTOB271 resulted in a dosedependent inhibition of tumor growth, and animals did not lose $>10 \%$ of their body weight during treatment (Figure 1e, lower panel).

MРТОВ271 inhibits cancer cell proliferation and induces cytotoxicity in vitro. The ability of MPTOB271 to inhibit cancer cell growth was evaluated using the Sulforhodamine $\mathrm{B}$ (SRB) assay. As shown in Figure 2a, MPT0B271 inhibited the proliferation of A549, AsPC-1, HCT116, Hep3B, MDAMB-231, PC3, SKOV3, and NCI/ADR-RES cells with $\mathrm{GI}_{50}$ values of $27.9,23.3,21.0,35.5,19.0,20.4,18.5$, and $18 \mathrm{nM}$, respectively. MPTOB271 reduced the viability of several human cancer cell lines with $\mathrm{IC}_{50}$ values in the low nanomolar range of $21-73 \mathrm{nM}$, as measured by the 3-(4,5dimethylthiazol-2-yl)-2,5-diphenyltetrazolium bromide (MTT) assay (Figure $2 b$ ).

Effects of paclitaxel and vincristine on the growth of NCI/ADR-RES cells. MPTOB271 was equally potent against the multidrug-resistant cancer cell line NCl/ADR-RES, as measured by both SRB and MTT assays. The growth inhibition of $\mathrm{NCl} / \mathrm{ADR}-\mathrm{RES}$ cells treated with paclitaxel or vincristine was then evaluated. As shown in Figure $2 \mathrm{c}$, the mean $\mathrm{Gl}_{50}$ values of paclitaxel and vincristine were $7.670 \pm 1.228 \mu \mathrm{M}$ and $8.156 \pm 0.854 \mu \mathrm{M}$, respectively, indicating that the effect of MPTOB271 was more potent than that paclitaxel or vincristine in NCI/ADR-RES cells. Next, we performed flow cytometric analysis to measure the accumulation of rhodamine-123 (Rh-123), a P-gp-transported fluorescent dye, in NCl/ADR-RES cells following the treatment with MPTOB271. After incubation with classic P-gp inhibitors, verapamil and cyclosporine $A$, we observed a large increase in Rh-123 accumulation in comparison with the vehicle-treated cells. However, Rh-123 accumulation did not increase in $\mathrm{NCl}$ /ADR-RES cells after incubation with MPTOB271 (Figure 2d). Calcein acetoxymethyl ester (calcein AM) is a fluorescent substrate for P-gp and can therefore be used to measure the transport activity of P-gp. Thus, P-gp inhibition was examined by measuring calcein AM retention using the Multidrug Resistant Assay. ${ }^{24}$ As illustrated in Figure 2e, the increase in intracellular fluorescence was indicative of $\mathrm{P}$-gp inhibition by verapamil or cyclosporine $A$. In contrast, the efflux of calcein AM was not affected by MPT0B271. These results suggest that MPTOB271 circumvents P-gp-mediated drug resistance.

MPTOB271 arrests the cell cycle in M phase. Most tubulin-targeting agents induce cell-cycle arrests; ${ }^{4}$ therefore, the effect of MPTOB271 on cell-cycle progression was assessed by FACScan flow cytometry using propidium iodide $(\mathrm{PI})$ staining. The data showed that treatment of 
a<smiles>COc1ccc(S(=O)(=O)N2CCc3cccc(NC(=O)c4cc[n+]([O-])cc4)c32)cc1</smiles>

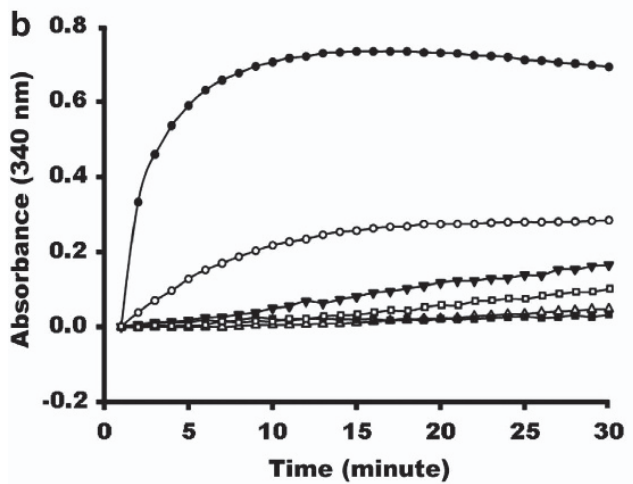

C
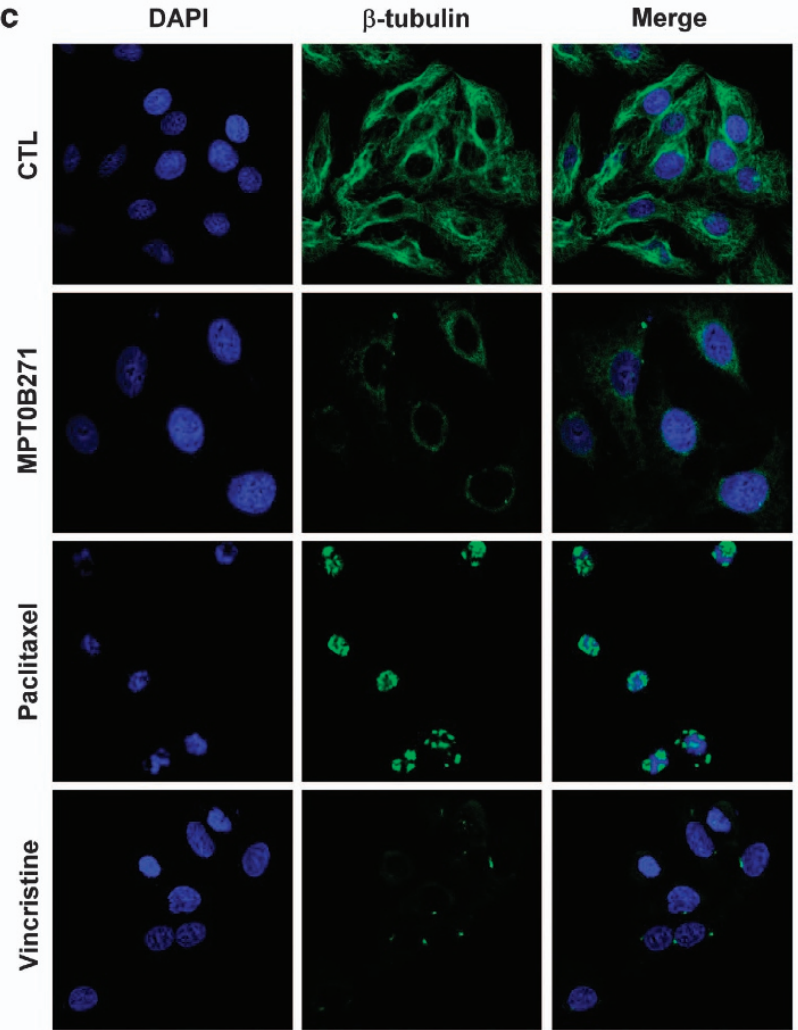

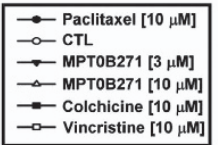

d
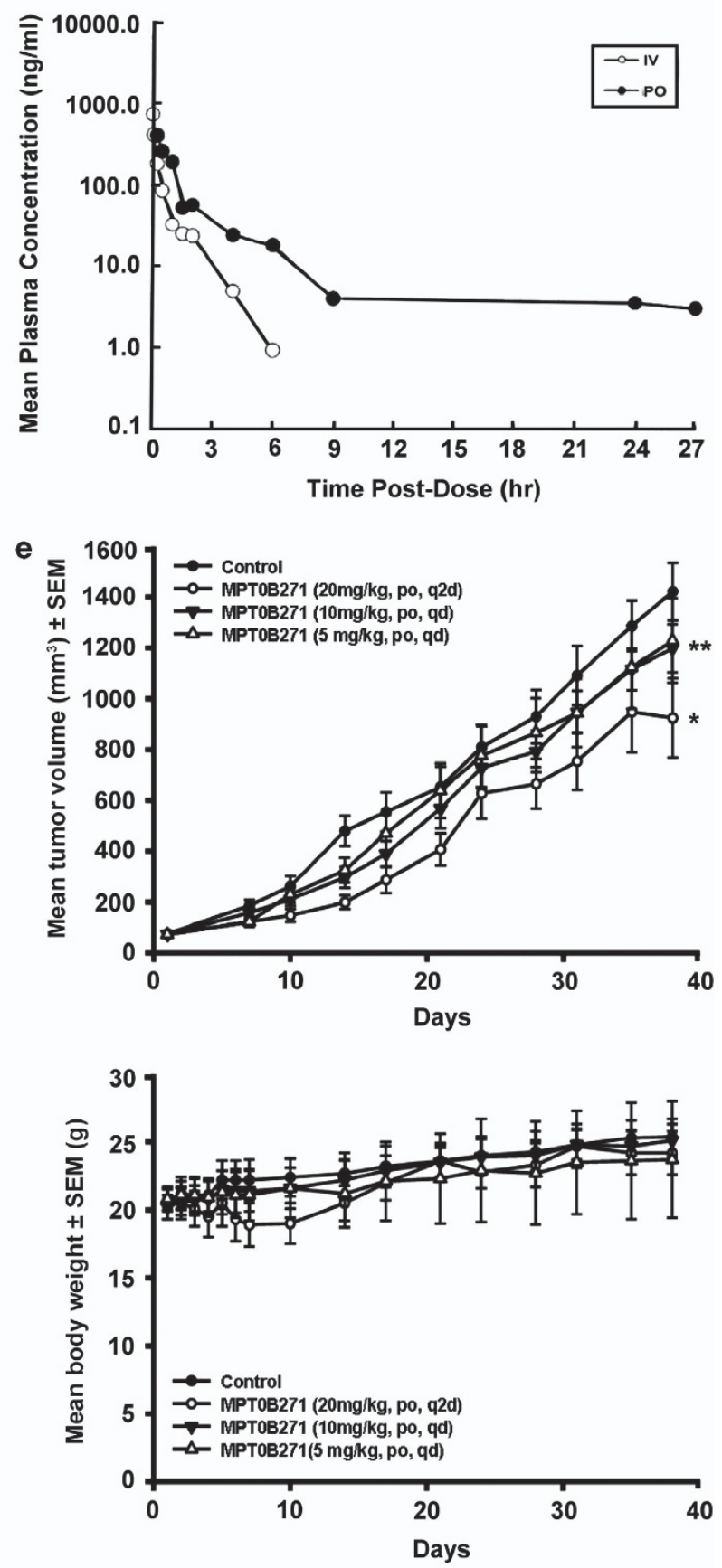

Figure 1 (a) Chemical structure of MPTOB271. (b) Effect of MPTOB271 on tubulin polymerization. Purified tubulin in reaction buffer was incubated at $37^{\circ} \mathrm{C}$ in the absence or presence of increasing concentrations of MPTOB271, $10 \mu \mathrm{M}$ paclitaxel, $10 \mu \mathrm{M}$ colchicine, or $10 \mu \mathrm{M}$ vincristine. Assembly of microtubules was then measured over 30 min at 1 min intervals at an absorbance of $340 \mathrm{~nm}$ using a spectrophotometer. (c) Immunofluorescence staining of microtubules in A549 cells. Cells were treated with vehicle (DMSO), $0.3 \mu \mathrm{M}$ MPTOB271, paclitaxel, or vincristine for $24 \mathrm{~h}$. Cells were labeled with a $\beta$-tubulin antibody and an FITC-conjugated anti-mouse IgG antibody, were counterstained with 4,6-diamidino-2-phenylindole (DAPI) and observed by confocal microscopy. Left, DAPI; middle, microtubule network; right, merged microtubule network and DAPI. (d) PK properties, plasma concentration versus time profiles of MPT0B271 after i.v. (2 mg/kg) and p.o. (20 mg/kg) dosing of fasted male CD-1 (Crl.) mice. (e) Efficacy of MPTOB271, dosed orally, on tumor xenografts. Upper panel, tumor growth of A549 xenografts in nude mice that were orally treated with or without MPT0B271 $(5,10$, and $20 \mathrm{mg} / \mathrm{kg})$. Tumor growth is presented as the mean tumor volume $\left(\mathrm{mm}^{3}\right) \pm S$.E. Tumor volume was determined using caliper measurements and was calculated as the product of $1 / 2 \times$ length $\times$ width $^{2}$. Lower panel, body weight $(\mathrm{g})$ of the mice. ${ }^{*} P<0.05$ and ${ }^{\star *} P<0.01$ as compared with the control group 
a

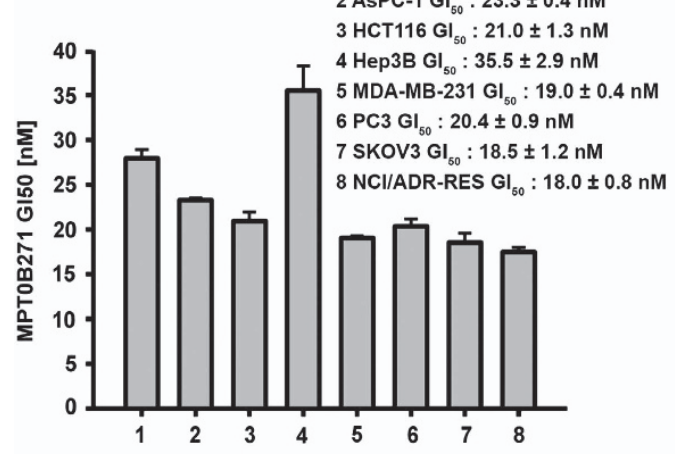

b

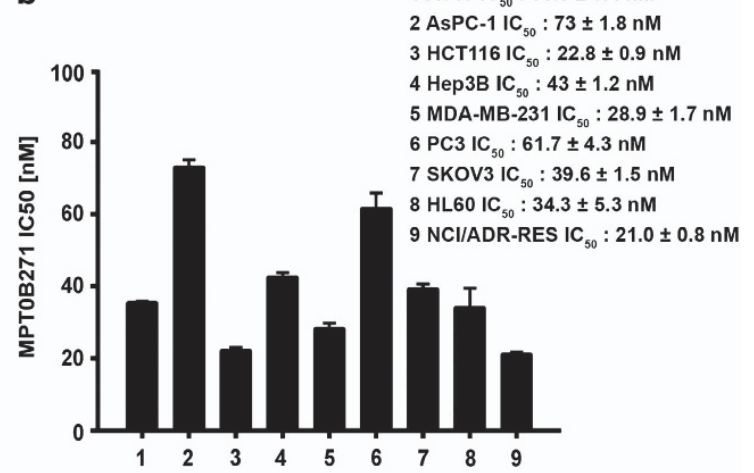

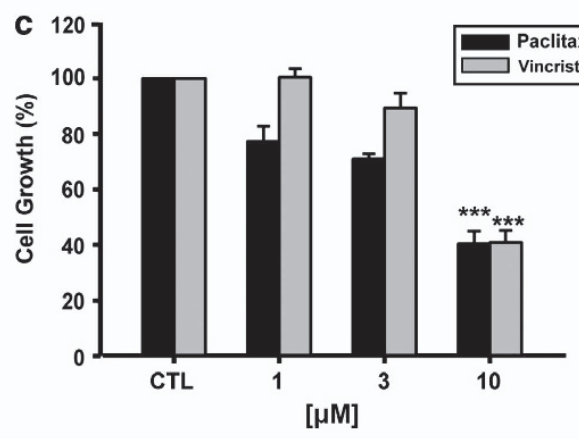

d
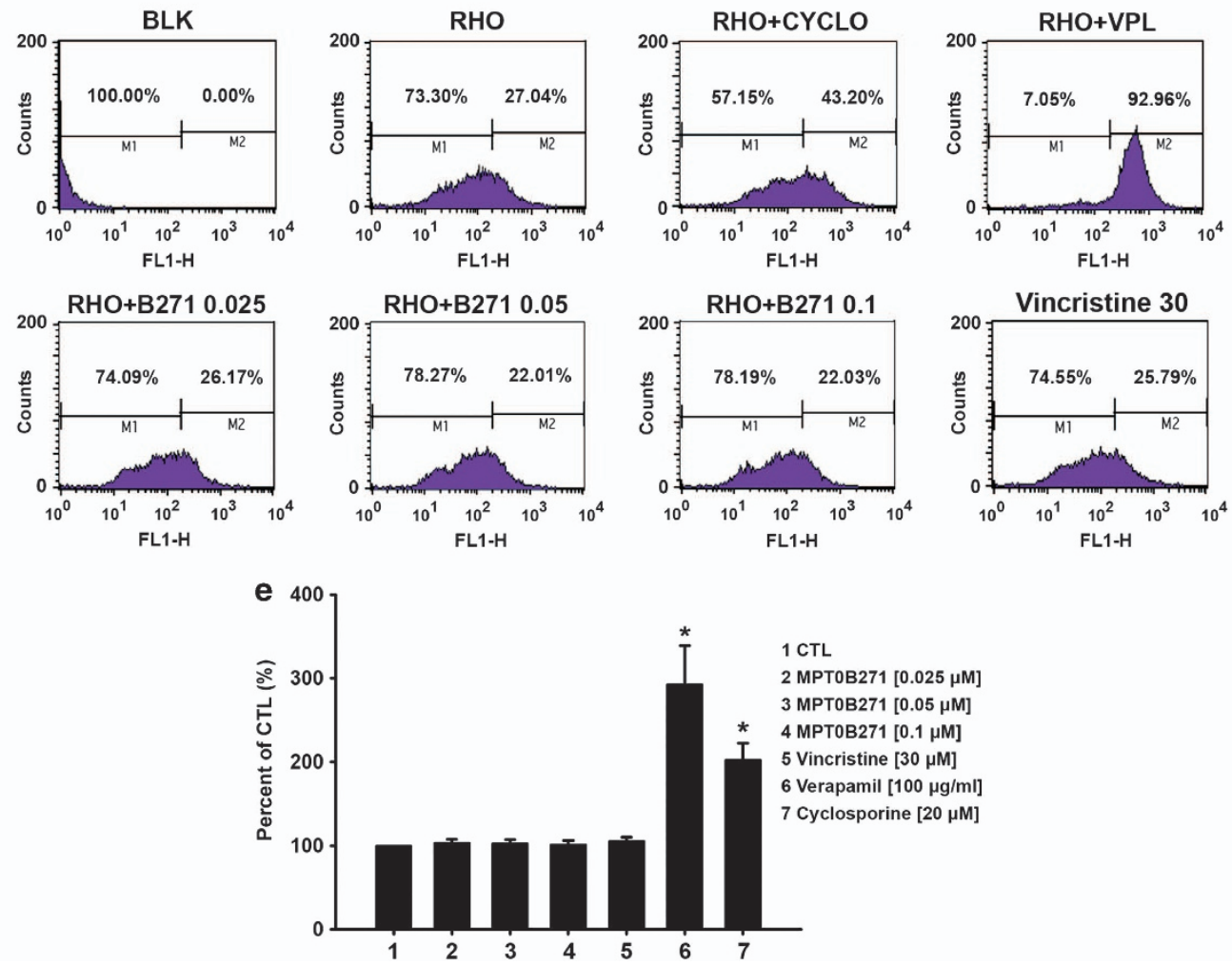

Figure 2 (a) Various types of human cancer cells were treated with the indicated concentrations of MPTOB271 for $48 \mathrm{~h}$. Then, cell growth inhibition was determined using the SRB assay, and the $\mathrm{Gl}_{50}$ of each cell line is expressed as the mean $\pm \mathrm{S}$.E. of four independent determinations. (b) The cytotoxic effects of various human cancer cell lines were determined using an MTT assay. The $\mathrm{IC}_{50}$ of each cell line is expressed as the mean \pm S.E. of four independent determinations. (c) NCI/ADR-RES cells were treated with the indicated concentration of paclitaxel or vincristine for $48 \mathrm{~h}$, and cell growth was determined by the SRB assay. Data are expressed as the mean \pm S.E. of at least three independent experiments. ${ }^{* * *} P<0.01$ as compared with the control group. (d) Effect of MPTOB271 on P-gp activity. NCl/ADR-RES cells were pretreated with or without MPTOB271 (0.025, 0.05 , and $0.1 \mu \mathrm{M}$ ), verapamil $(50 \mu \mathrm{M})$, cyclosporine $\mathrm{A}(10 \mu \mathrm{M})$, or vincristine $(30 \mu \mathrm{M})$ for $1 \mathrm{~h}$ and then co-treated with $10 \mu \mathrm{M}$ rhodamine $123(\mathrm{Rh}-123)$. After $1 \mathrm{~h}$ incubation at $37^{\circ} \mathrm{C}$, cells were washed with PBS, collected by trypsinization and detected by flow cytometry. (e) NCI/ADR-RES cells were incubated in the absence or presence of the indicated agents for 30 min and then stained with calcein AM fluorescent dye. Fluorescence was measured at an excitation wavelength of $485 \mathrm{~nm}$ and an emission wavelength of $535 \mathrm{~nm}$. ${ }^{*} P<0.05$ as compared with the control group 
A549 cells with MPT0B271 for $6-72 \mathrm{~h}$ resulted in a timedependent accumulation of cell populations at the G2/M phase followed by a subsequent increase in the hypodiploid sub-G1 cell population, which indicated apoptosis (Figure 3a). To elucidate the mechanisms through which MPTOB271 induced the G2/M-phase arrests, the levels of the G2/M phase regulatory proteins were assessed. Western blot analysis revealed that MPTOB271 induced upregulation of cyclin B1, p-Thr161 Cdc2/p34, serine/threonine kinases polo-like kinase 1 (PLK1), and aurora kinase $A$ and $B$; downregulation of Cdc25C and p-Tyr15 Cdc2/p34 protein levels; and a marked increase in mitosis-specific MPM2 phosphoprotein expression (Figure 3b). In addition, a remarkable nuclear accumulation of cyclin B1 protein was demonstrated in MPTOB271-treated A549 cells as compared with untreated cells (Figure $3 c$ ).

MPTOB271 triggers apoptosis in A549 cells. The ability of MPTOB271 to induce apoptosis was examined by measuring cytoplasmic histone-associated DNA fragments using the Cell Death Detection ELISA ${ }^{\text {Plus }}$ kit. The data show that increasing concentrations of MPTOB271 increased the level of DNA fragments in A549 cells after $48 \mathrm{~h}$ of treatment (Figure 4a). Moreover, MPTOB271 caused a concentrationdependent increase in cleaved executioner caspase- 3 and its downstream substrate poly (ADP-Ribose) polymerase (PARP) (Figure 4b). Based on these results, we investigated the effect of MPTOB271 on the expression of anti-apoptotic proteins. The protein levels of $\mathrm{Bcl}-2, \mathrm{Bcl}-\mathrm{xL}$, and $\mathrm{Mcl}-1$ in A549 cells decreased in a time-dependent manner after MPTOB271 treatment (Figure 4c). Furthermore, exogenous Mcl-1 overexpression partially abolished the activation of PARP cleavage and rescued cell viability in A549 cells, suggesting that MPTOB271 triggers apoptotic cell death through the suppression of Mcl-1 expression (Figure 4d).

MPTOB271 inhibits constitutive p53 activation in A549 cells. The effect of MPTOB271 on p53 was evaluated by treating A549 cells for 6-48 $\mathrm{h}$ with MPTOB271 and then by immunoblotting with p53 and phospho-p53 (Ser15) antibodies. Treatment with MPTOB271 upregulated the expression of p53 protein and the phosphorylation of p53 at Ser15 (Figure 5a). However, knockdown of p53 by p53 small interfering RNA (siRNA) did not attenuate the induction of PARP and prevent the cytotoxic effects (Figure $5 \mathrm{~b}$ ). In addition, we further evaluated the in vitro cytotoxic activities of MPTOB271 in other human NSCLC cell lines, H1299 (null p53) and H226 (mutant p53), using the MTT assay. Treatment of $\mathrm{H} 1299$ and $\mathrm{H} 226$ cells with MPTOB271 reduced cell viability in a concentration-dependent manner, with mean $\mathrm{IC}_{50}$ values of $0.110 \pm 0.014 \mu \mathrm{M}$ and $0.046 \pm 0.003 \mu \mathrm{M}$, respectively (Figure $5 \mathrm{c}$ ).

MPTOB271 inhibits constitutive STAT3 activation in A549 cells. Next, we investigated the effect of MPTOB271 on the modulation of constitutive STAT-3 phosphorylation in A549 cells by western blot analysis using an antibody that recognizes phosphorylation at Tyr705. As shown in Figure 5d, MPTOB271 significantly inhibited the constitutive phosphorylation of STAT3 in a time-dependent manner. The level of
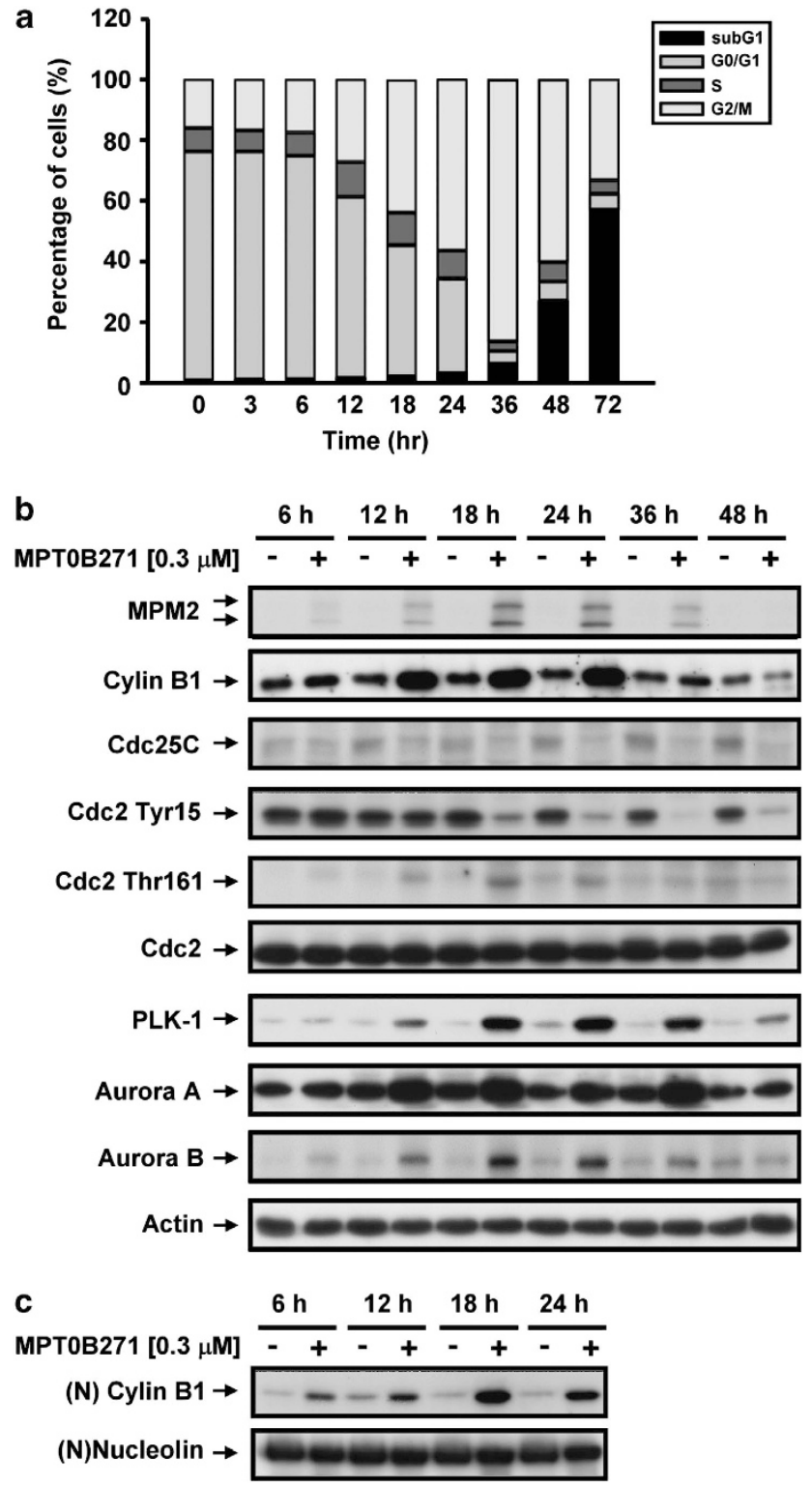

Figure 3 (a) Effect of MPTOB271 on cell-cycle progression. A549 cells were exposed to $0.3 \mu \mathrm{M}$ MPTOB271 for the indicated times and then stained with PI to determine the proportion of DNA. Data acquisition and analysis were performed on a FACScan flow cytometer. The data are expressed as the mean \pm S.E. of at least three independent experiments. (b) The effect of MPT0B271 on G2/M cell-cycle regulatory proteins. A549 cells were treated with $0.3 \mu \mathrm{M}$ MPTOB271 for the indicated times. Whole-cell extracts were subjected to SDS-PAGE and immunoblotted with the indicated antibodies. (c) Treatment with $0.3 \mu \mathrm{M}$ MPTOB271 for the indicated times. Nuclear lysates were subjected to western blot analysis using an antibody specific for cyclin B1

STAT3 tyrosine phosphorylation declined dramatically in MPTOB271-treated A549 cells, as determined by the PathScan Phospho-STAT3 (Tyr705) Sandwich ELISA kit (Figure 5e). However, transfection with constitutively active STAT3 only slightly rescued cell viability in A549 cells (Figure 5f).

MPT0B271 in combination with erlotinib increased tumor cell growth inhibition in vitro and in vivo. Erlotinib has proven efficacy in advanced NSCLC, but resistance to 

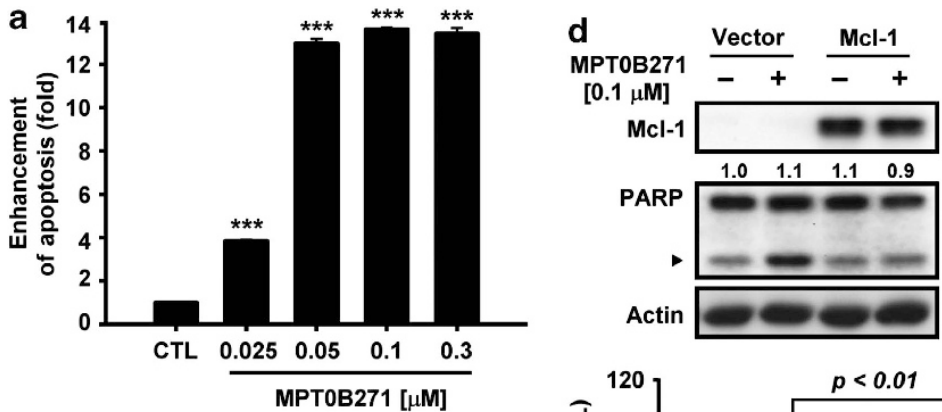

b

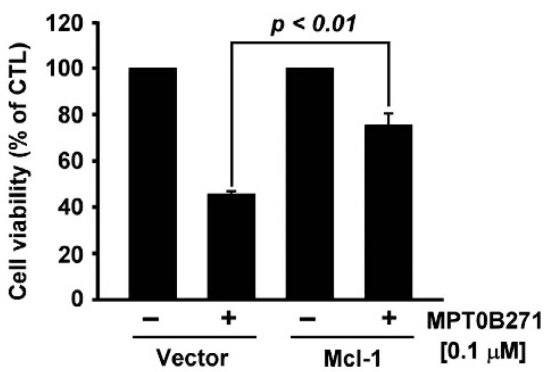

cleaved caspase-7 $\square$

MPTOB271 procaspase-3 $=-\infty-\infty$

cleaved caspase-3

$\pm=$

procaspase-7 ---

procaspase-8 $\square$

procaspase-9 $\longrightarrow$

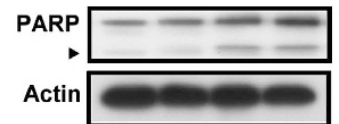

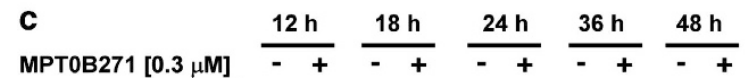

Mcl-1 $\mathrm{Oen- \infty}$

Bcl-2

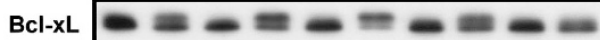

Bid $=-\infty-6-6$

$\operatorname{Bax}=2 \equiv \equiv \equiv \equiv \equiv=$

Actin $-\infty-\infty-\infty-\infty$

Figure 4 (a) Measurement of apoptosis. A549 cells were treated with the indicated concentration of MPTOB271, and oligonucleosomal DNA fragmentation was quantitatively assessed with the Cell Death ELISA ${ }^{\text {PLUS }}$ kit. Apoptosis was enhanced in relation to control cells. Data are expressed as the mean \pm S.E. of at least three independent experiments. ${ }^{* \star}{ }^{*} P<0.001$, as compared with the control group. (b) A549 cells were exposed to serial concentrations of MPTOB271 for $48 \mathrm{~h}$, and whole-cell lysates were collected and immunoblotted with antibodies against caspase- $-3,-7,-8$, and -9 and PARP. (c) After treatment with vehicle or MPTOB271 (0.3 $\mu$ M) for the indicated times, A549 cells were harvested and lysed. Equal amounts of lysate protein were run on an SDS-PAGE gel, transferred onto nitrocellulose membrane and incubated with the indicated antibodies. (d) Effect of ectopic Mcl-1 on MPTOB271-induced cell apoptosis. A549 cells were transfected with vector or Mcl-1 plasmid for $24 \mathrm{~h}$ and then incubated with or without MPTOB271 for $48 \mathrm{~h}$. Whole-cell lysates were subjected to western blot analysis, and cell viability was measured by the SRB assay

erlotinib also occurs. ${ }^{23}$ Thus, we investigated whether the combination of erlotinib and MPTOB271 is effective against erlotinib-resistant human NSCLC A549 cells. We chose these concentrations from dose-response curves (data not shown). As shown in Figure 6a and Supplementary Figure 2, erlotinib $(5 \mu \mathrm{M})$ in combination with MPTOB271 $(0.0125$ or $0.025 \mu \mathrm{M})$ resulted in significantly higher cell death than the monotherapeutic treatments, as measured using an enzyme immunoassay for histone-associated DNA fragments. Finally, treatment of A549 xenograft-bearing nude mice with a combination of erlotinib and MPTOB271 resulted in significantly decreased tumor progression without loss of their body weight as compared with either erlotinib or MPT0B271 monotherapy (Figures $6 b$ and $c$ ). These data indicate that erlotinib in combination with MPTOB271 is effective against erlotinib-resistant NSCLC cell lines.

\section{Discussion}

In the present study, МРTOB271 was identified as a microtubule-depolymerizing agent and exhibited significant antitumor activity against various cancer cell lines, as well as drug-resistant sublines. It has been illustrated that p53 serves as a key player in cellular response to various extracellular and intracellular stresses such as DNA damage, oncogenic action, and microtubule disruption. ${ }^{25}$ Our results showed that MPTOB271 induces the expression of p53 protein in a timedependent manner, but the knockdown of p53 cannot prevent 

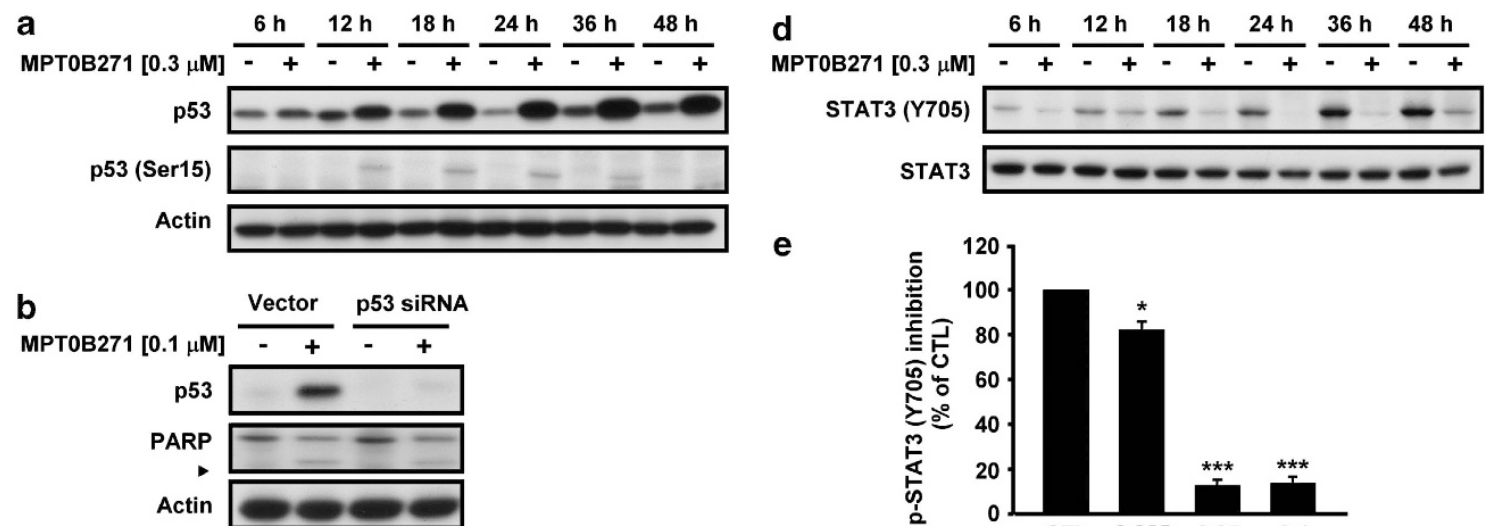

e
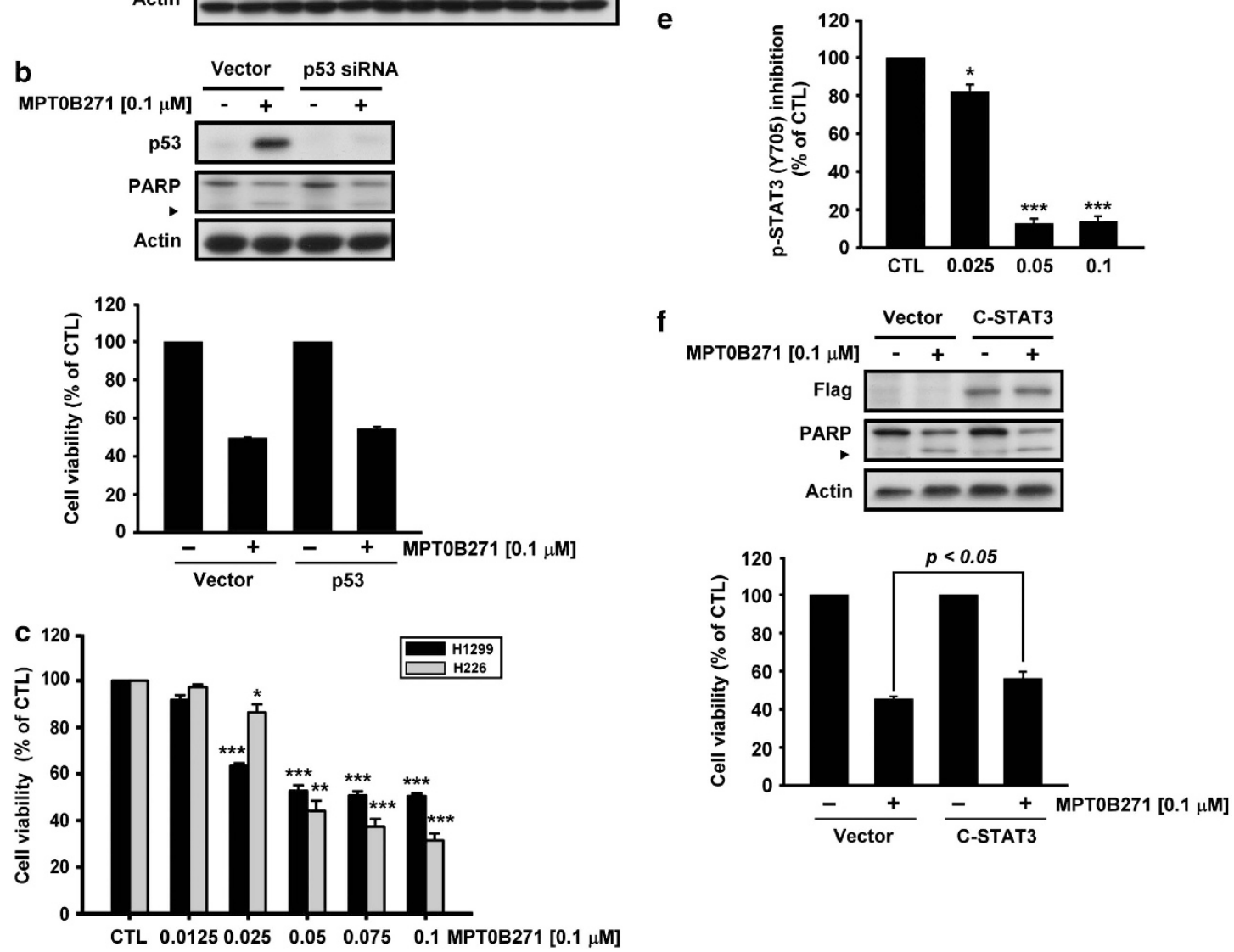

Figure 5 (a) The effect of MPTOB271 on p53 expression and phosphorylation in A549 cells. Cells were treated with MPTOB271 $(0.3 \mu \mathrm{M})$ for the indicated times, and whole-cell extracts were prepared and underwent western blot analysis using the indicated antibodies. (b) A549 cells were pretreated with or without p53 siRNA for $24 \mathrm{~h}$ and then incubated with or without MPTOB271 $(0.1 \mu \mathrm{M})$ for $48 \mathrm{~h}$. Upper panel, total cellular lysates were subjected to western blot analysis of p53 and PARP. Lower panel, cell viability was measured by the SRB assay and expressed as a percentage of the untreated control. (c) Concentration-dependent effect of MPTOB271 on cell viability. H1299 and H226 cells were treated with or without the indicated concentration of MPTOB271 for $48 \mathrm{~h}$, and the cytotoxic effect was determined with the MTT assay. Data are expressed as the mean \pm S.E. of at least three independent experiments. ${ }^{*} P<0.05$; ${ }^{* *} P<0.01$, and ${ }^{* * *} P<0.001$ as compared with the control group. (d) The effect of MPTOB271 on STAT3 phosphorylation in A549 cells. Cells were treated with MPTOB271 $(0.3 \mu \mathrm{M})$ for the indicated times, and whole-cell extracts were prepared and analyzed for STAT-3 phosphorylation (at Tyr ${ }^{705}$ ). (e) A549 cells were treated with various concentrations $(0.025-0.1 \mu \mathrm{M})$ of MPTOB271 for $24 \mathrm{~h}$, after which the level of STAT3 tyrosine phosphorylation in cells was measured using the PathScan Phospho-Stat3 (Try705) Sandwich ELISA kit and spectrophotometry at $450 \mathrm{~nm}$. Data represent the mean \pm S.E. of at least three independent experiments. ${ }^{*} P<0.05$; ${ }^{\star \star *} P<0.001$ as compared with the control group. (f) The effect of ectopic STAT3 on MPTOB271-induced cell apoptosis. A549 cells were transfected with vector or STAT3 plasmid for $24 \mathrm{~h}$ and then incubated with or without MPTOB271 for $48 \mathrm{~h}$. Whole-cell lysates were subjected to western blot analysis, and cell viability was measured by the SRB assay

apoptosis in cells treated with MPTOB271. In addition, A549 (wild-type p53), H1299 (p53 null), and H226 (p53 mutant) exhibited similar $\mathrm{IC}_{50}$ values, indicating that the antitumor effect of MPTOB271 may not correlate with the p53 status. The traditional microtubule-targeting agents in clinical use, such as paclitaxel, require intravenous administration with a long-term remedial course, causing physical and mental suffering and reducing the patients' quality of life. In addition, they often lead to hypersensitivity reactions and neuropathy. ${ }^{26,27}$ Here, it is noteworthy that MPT0B271 possesses oral availability, improves solubility, and is efficacious in vivo against NSCLC tumor xenografts.
Drug resistance is a serious problem that restricts the use of microtubule-targeting agents for clinical therapy. The MDR $\mathrm{P}$-gp, a plasma membrane protein overexpressed in multidrug-resistant tumor cells, is a major obstacle to the success of chemotherapy. Efflux of drugs caused by MDR proteins augments the elimination of drugs from target cells and leads to drug resistance. ${ }^{28}$ Many microtubule-targeting agents are substrates of P-gp, and higher doses of these drugs are required to achieve adequate intracellular concentrations in multidrug-resistant cancer cells. ${ }^{8}$ We employed Rh-123 and calcein AM, both substrates of $P$-gp and multidrug resistanceassociated protein (MRP), as probes to detect chemical 
a
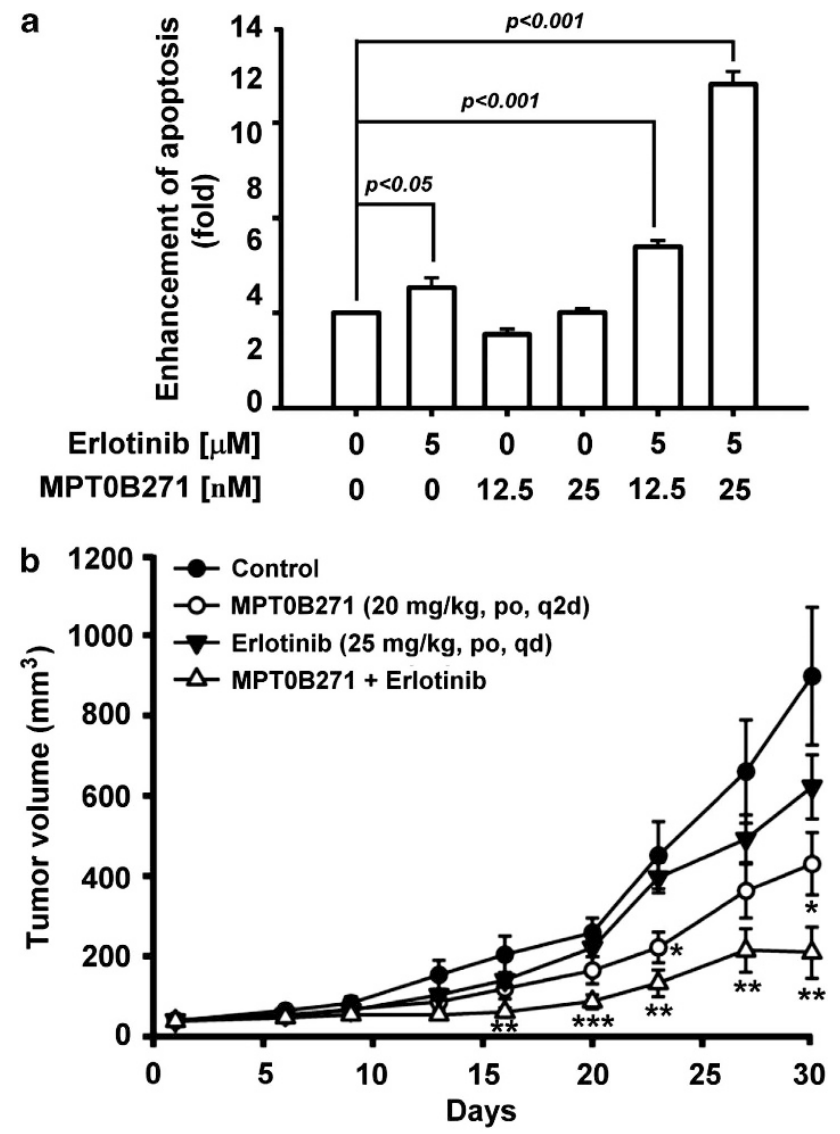

C

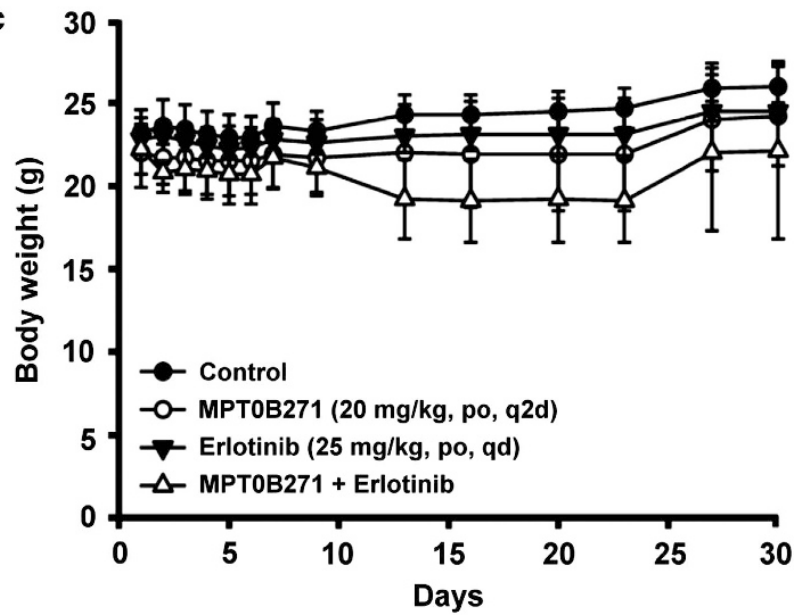

Figure 6 In vitro and in vivo antitumor activity of MPTOB271 in combination with erlotinib. (a) A549 cells were treated with erlotinib $(5 \mu \mathrm{M})$ in combination with MPTOB271 $(0.0125$ or $0.025 \mu \mathrm{M})$ for $48 \mathrm{~h}$, and cell apoptosis was measured using the Cell Death ELISA ${ }^{\text {PLUS }}$ kit. Data are expressed as the mean \pm S.E. of at least three independent determinations. (b) A549 xenograft model. A549-tumor-bearing nude mice were treated with vehicle, MPTOB271 $(20 \mathrm{mg} / \mathrm{kg} /$ day by oral gavage q2d), erlotinib $(25 \mathrm{mg} / \mathrm{kg} /$ day by oral gavage once a day), or MPTOB271 in combination with erlotinib. Tumor was excised when the tumor size reached $1200 \mathrm{~mm}^{3}$. (c) The body weight of the mice measured daily during the first week and then at the days of administration. ${ }^{*} P<0.05$; ${ }^{* \star} P<0.01$, and ${ }^{* \star *} P<0.001$ as compared with the control group

compounds interacting with MDR proteins. The calcein generated from calcein AM by esterase in a viable cell emits strong green fluorescence. ${ }^{24,29,30}$ Our results demonstrated that the accumulation of Rh-123 or the intracellular fluorescence of Calcein is not increased in MPTOB271-treated NCl/ ADR-RES cells. We also tested the effect of verapamil in combination with MPTOB271 using SRB assay (Supplementary Figure 1). The $\mathrm{GI}_{50}$ values of the combination of verapamil with MPTOB271 in NCl/ADR cells were $16 \mathrm{nM}$, which indicated that the antiproliferative effect of combination was similar with that of treatment with MPTOB271 alone. These results demonstrated that MPTOB271 may not be a substrate or modulator of the P-gp efflux pump.

Similar to other microtubule-targeting agents, MPTOB271 induced a concentration-dependent G2/M blockade, as indicated by flow cytometric analysis and expression of the MPM-2 epitope, a mitosis-specific marker. Another marker of the G2/M phase is cyclin B1, which is localized in the cytoplasm in G2 phase but moves rapidly into the nucleus at the beginning of mitosis. ${ }^{31}$ Western blot analysis showed that the protein level of cyclin B1 in the nuclear fraction of MPTOB271-treated cells was significantly enhanced compared with that of untreated cells, implying that cells treated with MPTOB271 were arrested in the mitotic phase. Cdc2/p34 is a cell-cycle kinase responsible for the regulation of $\mathrm{G} 2$ progression and G2/M transition in all eukaryotic cells. It has been reported that the activity of Cdc2/ p34 kinase depends not only on its association with cyclin B1 but also on its phosphorylation state. ${ }^{32}$ We found that MPTOB271 markedly reduced p-Tyr15 Cdc2/p34 levels and increased p-Thr161 Cdc2/p34 levels and was associated with cyclin B1 upregulation, but had no effect on Cdc2/p34 expression. The PLK-1 and aurora kinase $A$ and $B$ are active during mitosis. ${ }^{33}$ PLK-1 is an early trigger of G2/M transition in mammalian cells and has been implicated in the regulation of different processes including mitotic entry, spindle formation, and cytokinesis. Aurora kinase $A$ and $B$ are required for centrosome separation, mitotic spindle assembly, chromosome biorientation, and cytokinesis during mitosis. ${ }^{34,35}$ Our results showed that MPTOB271 enhances the expression of PLK-1 and aurora kinase $A$ and $B$ proteins in a time-dependent manner, supporting the notion that MPTOB271 induces M-phase arrest in A549 cells.

Our results showed that in addition to inducing cell-cycle arrests in mitosis, treatment with MPTOB271 is followed by a subsequent increase in the hypodiploid (apoptotic sub-G1 peak) population of the cell cycle. The presence of cytoplasmic histone-associated DNA fragments induced by MPTOB271 was also observed, providing additional evidence that MPT0B271 induces apoptosis in A549 cells. Cysteine proteases (caspases) have a critical role in apoptosis through the proteolysis of specific targets. Both the death receptormediated pathway and the mitochondrial-mediated pathway result in the activation of caspase-3, and subsequently lead to the cleavage of PARP. ${ }^{36}$ Our results showed that treatment with MPTOB271 results in a significant induction of caspase-3 and -7 activation, but fails to promote the cleavage of caspase8 and -9 in A549 cells. Caspases- 8 and -9 probably have a minor role in apoptosis in A549 cells. Mcl-1 is required to prevent apoptosis induced by intrinsic and extrinsic pathways. ${ }^{37}$ Treatment with MPTOB271 reduced the expression of Mcl-1 in A549 cells. In addition, cell apoptosis was rescued by exogenous $\mathrm{Mcl}-1$ overexpression, which signifies the role of Mcl-1 degradation in MPTOB271-induced cell apoptosis. 
STAT3 is constitutively activated in most tumor cells and persistent STAT3 activation has been associated with both chemoresistance and radioresistance. The acetyl STAT3 translocates into the nucleus where it promotes cell proliferation and survival through transactivation of related genes. In addition, STAT3 can also associate with microtubules and mitochondria and regulate cell behavior. It was found that microtubule-targeting agents decrease the tyrosine phosphorylation-induced activation of STAT3 (Tyr705) in tumor cells, inhibit the expression of STAT3 target genes, and correlate with its cytotoxic effect. ${ }^{38-40}$ In our study, we found that MPTOB271 specifically reduced STAT3 phosphorylation at Tyr705. In A549 cells transfected with the STAT3-C plasmid, a minor reversal of cell cytotoxicity was observed, suggesting that STAT3 may have a minor role in MPTOB271induced apoptosis in A549 cells and that other mechanisms may be involved in this phenomenon.

The overexpression of EGFR has previously been reported in a wide range of human malignancies including NSCLC and is a factor that is indicative of poor prognosis. The oral EGFR tyrosine kinase inhibitor Erlotinib (Terceva, Roche, Mannheim, Germany) reversibly binds to the intracellular domain of EGFR and blocks autophosphorylation of EGFR with subsequent suppression of the downstream signaling pathways that causes uncontrolled tumor cell growth and proliferation. Although erlotinib has proven efficacy in metastatic NSCLC and has been reported to confer a survival benefit for advanced NSCLC patients harboring EGFR mutations, resistance to erlotinib also occurs and reduces its efficacy. ${ }^{41-43}$ To overcome the problem of resistance, we combined the microtubule-binding agent MPTOB271 with erlotinib to increase the antitumor effects in the erlotinib-resistant human NSCLC cell line A549. Our data showed that erlotinib monotherapy did not result in significant cell death in A549 cells as compared with the control group, which was assessed using a cell death detection ELISA assay kit. However, combination therapy of MPTOB271 with erlotinib showed a synergistic effect in A549 cells. A similar result was obtained in the A549 subcutaneous xenograft mouse model. Erlotinib had no effect on tumor progression, but in comparison with MPTOB271 could produce a stronger antitumor effect. These results may indicate that MPTOB271 in combination with erlotinib would be a useful treatment in cases of NSCLC, which have developed progressive disease.

Taken together, our results indicated that MPT0B271 could be an effective orally administered microtubule-destabilizing agent with poor susceptibility to P-gp that possesses potent cytotoxic activity. We demonstrated that MPTOB271 inhibits tubulin polymerization, leading to mitotic arrest of the cell cycle and subsequently triggering apoptotic signaling pathways in human NSCLC cells. In addition, the antitumor growth effect of MPTOB271 in combination with the EGFR inhibition effect of erlotinib is more potent than the same drug used alone in NSCLC cells in vitro and in vivo. These findings suggest that MPTOB271 may foster novel therapeutic strategies for NSCLC.

\section{Materials and Methods}

Reagents. SRB (230162; Sigma-Aldrich, St. Louis, MO, USA), MTT (M2128; Sigma-Aldrich), PI (P4170; Sigma-Aldrich), FITC-conjugated anti-mouse IgG (F9295; Sigma-Aldrich), and all other chemical reagents were obtained from
Sigma (St. Louis, MO, USA). 4',6-diamidino-2-phenylindole (DAPI) was purchased from Roche Molecular Biochemicals (Cat. 10236276001, Mannheim, Germany). Antibodies against cdc2 (Thr161) (Cat. 9114), cdc2 (Tyr15) (Cat. 4539), Aurora A (Cat. 4718), Aurora B (Cat. 3094), PLK1 (Cat. 4513), p53 (Sser15) (Cat. 2527), Bid (Cat. 2002), caspase-8 (Cat. 9746), and caspase-9 (Cat. 9502) were purchased from Cell Signaling Technology (Beverly, MA, USA). Antibodies against cyclin B1 (Cat. sc-594), cdc25C (Cat. sc-13138), cdc2 (Cat. sc-54), Bcl-2 (Cat. sc7382), Bcl-xL (Cat. sc-8392), Bax (Cat. sc-7480), Mcl-1 (Cat. sc-819), Bak (Cat. Sc-832), and PARP (Cat. sc-7150) were purchased from Santa Cruz Biotechnology (Santa Cruz, CA, USA). The antibody against caspase-3 (Cat. IMG144A) was purchased from Imgenex (San Diego, CA, USA), and the antibody to MPM2 (Ser161/Thr97) (Cat. 05-368) was obtained from Upstate Biotechnology Inc. (Temecula, CA, USA). Antibodies to STAT3 (Cat. 610189), p53 (Cat. 554166), and caspase-7 (Cat. 556541) were purchased from BD Biosciences (San Jose, CA, USA). The antibody to STAT3 (Tyr705) (Cat. 2236-1) was obtained from Epitomics (Burlingame, CA, USA), and the antibody to actin (Cat. MAB1501) was purchased from Millipore (Temecula, CA, USA). The p53 si RNA (Cat. 106141) was obtained from Invitrogen (Carlsbad, CA, USA).

Cell culture. The human NSCLC cell lines A549, NCl-H1299, and $\mathrm{NCl}-\mathrm{H} 226$; the human pancreatic adenocarcinoma cell line AsPC-1; the human colorectal cancer cell line HCT-116; the human hepatoma cell line Hep3B; the human breast carcinoma cell line MDA-MB-231; the human prostate cancer cell line PC-3; the human ovarian carcinoma cell line SKOV3; and the human promyelocytic leukemia cell line HL60 were obtained from American Type Culture Collection (ATCC) (Manassas, VA, USA). The NCI/ADR-RES cell line was obtained from the DTP Human Tumor Cell Line Screen (Developmental Therapeutics Program, NCl). Cells were maintained in RPMI-1640 medium or DMEM with $10 \%$ fetal bovine serum (FBS) and penicillin $(100 \mathrm{U} / \mathrm{ml}) /$ streptomycin $(100 \mu \mathrm{g} / \mathrm{ml}) /$ amphotericin $(0.25 \mu \mathrm{g} / \mathrm{ml})$ at $37^{\circ} \mathrm{C}$ in a humidified incubator with $5 \% \mathrm{CO}_{2}$.

In vitro tubulin polymerization assay. The effect of identified compounds on tubulin polymerization was determined kinetically using the CytoDYNAMIX Screen kit (BK006P, Cytoskeleton Inc., Denver, CO, USA). Cold porcine tubulin protein ( $>99 \%$ purity) was added to G-PEM buffer ( $80 \mathrm{mM}$ PIPES, $2 \mathrm{mM} \mathrm{MgCl}_{2}, 0.5 \mathrm{mM}$ EGTA, $1 \mathrm{mM}$ GTP, pH 6.9) containing $15 \%$ glycerol with or without the identified compounds. The sample mixture was dotted onto a prewarmed 96-well plate, which was immediately transferred to a $37^{\circ} \mathrm{C}$ plate reader (SpectraMax Plus, Molecular Devices Inc., Sunnyvale, CA, USA). The absorbance was read every minute for $30 \mathrm{~min}$ at $340 \mathrm{~nm}$.

Immunofluorescence confocal microscopy. A549 cells were seeded sparsely in eight-well chamber slides and treated with or without identified compounds for $24 \mathrm{~h}$. Following treatment, cells were fixed with cold methanol at $-20^{\circ} \mathrm{C}$ for $15 \mathrm{~min}$, washed three times with phosphate-buffered saline (PBS) and blocked with $1 \%$ PBS plus $0.1 \%$ Triton X-100 for 30 min at $37^{\circ} \mathrm{C}$. Microtubules were detected by incubation with a monoclonal anti- $\beta$-tubulin at $37^{\circ} \mathrm{C}$ for $1 \mathrm{~h}$. Then, the cells were washed with PBS and incubated with an FITC-conjugated anti-mouse $\operatorname{lgG}$ antibody. Nuclei were stained with DAPI, and microtubule distribution images were acquired with a Leica TCS SP2 Confocal Spectral Microscope (Leica, Wetzlar, Germany).

Pharmacokinetic analysis. Male CD-1 (Crl.) mice ( $n=4$ per group) were obtained from Lasco (Taipei, Taiwan) and used to examine the pharmacokinetics (PK) of the MPTOB271 compound. MPTOB271 was dissolved in polyethylene glycol 400/ethanol/water $(60 / 5 / 35, v / v)$ and administered by a single intravenous tail vein injection at $2.0 \mathrm{mg} / \mathrm{kg}$. For oral dosing, MPTOB271 was suspended in $0.5 \%$ methylcellulose $(\mathrm{MC}) /$ water and given via oral gavage with a dosing volume of $0.26 \mathrm{ml}$ per animal $(10 \mathrm{mg} / \mathrm{kg})$. The animals were fasted for $16 \mathrm{~h}$ before dosing and allowed to consume standard chow $4 \mathrm{~h}$ post dosing. For mice treated via tail vein injection, plasma samples were collected before dosing and then $2,5,15$, and 30 min and 1, 1.5, 2, 4, 6, 9, 24, and $27 \mathrm{~h}$ after dosing. For mice treated via oral administration, blood samples were collected before dosing and then 15 and 30 min and 1, 1.5, 2, 4, 6, 9, 24, and $27 \mathrm{~h}$ after dosing. The plasma concentrations of MPTOB271 were measured by LC-MS/MS (API4000; PE Sciex, Concord, ON, Canada) with a reverse-phase ODS column. The PK parameters were calculated from the mean plasma concentrations with the WinNonlin Professional program (version 5.2, Pharsight Corp., Mountain View, CA, USA). 
SRB assay. All cells were seeded in 96-well culture plates at a density of $3-5 \times 10^{3}$ cells/well. After attachment, cells were fixed with $10 \%$ trichloroacetic acid (TCA) to provide a measurement of the cell population at the time of drug addition. The following day, cells were treated with vehicle $(0.1 \% \mathrm{DMSO})$ or an increasing gradient concentration of the indicated compounds for $48 \mathrm{~h}$, after which cells were fixed with $10 \%$ TCA and stained with $0.4 \%(\mathrm{w} / \mathrm{v})$ SRB dissolved in $1 \%$ acetic acid. The protein-bound dye was subsequently extracted with $10 \mathrm{mM}$ trizma base to determine the absorbance at a wavelength of $515 \mathrm{~nm}$. The inhibition rate on cell proliferation $\left(\mathrm{Gl}_{50}\right)$ as a function of test drug concentration was calculated for each well as $100-\left[\left(\mathrm{A} 515_{\text {treated cells }}-\mathrm{A} 515_{\text {time }}\right)\right]$.

MTT assay. Cells were incubated in the absence or presence of MPTOB271 for $48 \mathrm{~h}$ and then incubated with $0.5 \mathrm{mg} / \mathrm{ml} \mathrm{MTT}$ solution for $1 \mathrm{~h}$ at $37^{\circ} \mathrm{C}$. At the end of the incubation, the purple formazan crystals were dissolved in $100 \mu \mathrm{l}$ DMSO, and the absorbance was measured at $550 \mathrm{~nm}$ using an ELISA reader. The percentage of cell survival was plotted as a percentage to determine the $\mathrm{IC}_{50}$ values (50\% growth inhibition).

P-gp activity assay. Rh-123 and a Multi-Drug Resistance Assay kit (Calcein AM, Cayman Chemical, Ann Arbor, MI, USA), both of which include fluorescent substrates of P-gp, were used to measure the transport activity of P-gp. For the Rh-123 assay, NCI/ADR-RES cells were pretreated with or without the indicated compounds in culture medium in the dark at $37^{\circ} \mathrm{C}$ for $1 \mathrm{~h}$ and then co-treated with $\mathrm{Rh}-123$ for an additional hour. After Rh-123 accumulation, the cells were washed with ice-cold PBS and collected by trypsinization. The intracellular fluorescence of Rh-123 was measured using a FACScan flow cytometer (BD Biosciences). The calcein AM efflux assay was performed according to the manufacturer's protocol. In brief, NCI/ADR-RES cells were seeded in 96-well culture plates at a density of $5 \times 10^{4}$ cells/well and then treated with or without the experimental compounds. Calcein AM was added to each well, and the fluorescence was measured at an excitation wavelength of $485 \mathrm{~nm}$ and an emission wavelength of $535 \mathrm{~nm}$.

Cell-cycle analysis. Following treatment, the cells were harvested by trypsinization and centrifuged. The pellets were fixed with $70 \%(\mathrm{v} / \mathrm{v})$ ethanol at $-20^{\circ} \mathrm{C}$ overnight. The cells were again centrifuged at 2000 r.p.m. for $3 \mathrm{~min}$, and the supernatant was discarded. Pellets were washed once with ice-cold PBS and resuspended in $0.1 \mathrm{ml}$ phosphate/citric acid buffer $\left(0.2 \mathrm{M} \mathrm{Na}_{2} \mathrm{HPO}_{4}, 0.1 \mathrm{M}\right.$ citric acid, $\mathrm{pH} \mathrm{7.8)} \mathrm{for} 30 \mathrm{~min}$ at room temperature. After incubation, the cells were stained with a PI working solution $(0.1 \%$ Triton X-100, $100 \mu \mathrm{g} / \mathrm{ml}$ RNase and $80 \mu \mathrm{g} / \mathrm{ml} \mathrm{PI}$ in PBS) in the dark. The fluorescence of the samples was measured with a FACScan flow cytometer with the CellQuest software (Becton Dickinson, San Jose, CA, USA).

Nuclear extracts and western blot analysis. Cytoplasmic and nuclear protein extraction was performed as described previously. ${ }^{44}$ For western blot analysis, cell lysates were prepared, and proteins were separated by $7.5-15 \%$ SDS-PAGE, transferred onto PVDF membrane, and then immunoblotted with specific antibodies. Proteins were visualized with an ECL detection system (GE Healthcare Bio-Sciences, Pittsburgh, PA, USA).

Evaluation of apoptosis. Quantitative oligonucleosomal DNA fragmentation was used to determine the ability of the identified compound to induce apoptosis. The Cell Death Detection ELISA ${ }^{\text {PLUS }}$ kit (Roche) was used according to the manufacturer's protocol.

STAT3 kit. The level of STAT3 phosphorylation in response to MPTOB271 treatment was determined using the PathScan Phospho-Stat3 (Try705) Sandwich ELISA kit (Cell Signaling Technology) according to the manufacturer's instructions. The absorbance was read within $30 \mathrm{~min}$ at $405 \mathrm{~nm}$ using a microplate ELISA reader.

Transient transfection. The siRNA against p53 and the negative control were purchased from Invitrogen. The Mcl-1 (25375) and STAT3-C plasmids were purchased from Addgene (Cambridge, MA, USA). A549 cells were grown to $70 \%$ confluence in a culture dish, and transfection was performed using Lipofectamine reagent (Invitrogen) according to the manufacturer's instructions. Following transfection, cells were allowed to recover for $24 \mathrm{~h}$, seeded in 96 -well or 6-well plates and then treated for another $48 \mathrm{~h}$.

A549 xenograft models. A549 cells $\left(2 \times 10^{6}\right.$ cells/mice $)$ in $0.2 \mathrm{ml}$ culture medium were inoculated subcutaneously (sc) in nu/nu mice (male, 5-6 weeks).
Once the tumor size was $\sim 100 \mathrm{~mm}^{3}$, mice were allocated at random to treatment groups: vehicle $\left(0.5 \% \mathrm{CMC} / 0.1 \%\right.$ Tween- 80 in $\left.\mathrm{ddH}_{2} \mathrm{O}\right) ; 5$ or $10 \mathrm{mg} / \mathrm{kg}$ of MPTOB271 once a day (qd) or $20 \mathrm{mg} / \mathrm{kg}$ once every 2 days (q2d) by oral gavage; $25 \mathrm{mg} / \mathrm{kg}$ of erlotinib qd; or $25 \mathrm{mg} / \mathrm{kg}$ of erlotinib qd in combination with $20 \mathrm{mg} / \mathrm{kg}$ of MPTOB271 q2d. Caliper measurements were used to calculate tumor volume $\left(V, \mathrm{~mm}^{3}\right)$ using the formula $V=I w^{2} / 2$, with $/$ being the length and the $w$ being the width of the tumor. All animal studies were conducted in accordance with the guidelines of the Animal Care and Use Committee at National Taiwan University.

Statistical analysis. Results are expressed as the mean \pm S.E. for the indicated number of separate experiments. Means were assessed for significant differences using $t$-test and $P$-values $<0.05$ were considered as significant.

\section{Conflict of Interest}

The authors declare no conflict of interest.

Acknowledgements. This work was supported by research grants from the National Science Council of Taiwan NSC 99-2320-B-038-020-MY3 and Taipei Medical University TMU101-AE1-B48.

1. Hawkins T, Mirigian M, Selcuk Yasar M, Ross JL. Mechanics of microtubules. J Biomech 2010; 43: 23-30.

2. Stanton RA, Gernert KM, Nettles JH, Aneja R. Drugs that target dynamic microtubules: a new molecular perspective. Med Res Rev 2011; 31: 443-481.

3. Schmidt M, Bastians $\mathrm{H}$. Mitotic drug targets and the development of novel anti-mitotic anticancer drugs. Drug Resist Updat 2007; 10: 162-181.

4. Mollinedo F, Gajate C. Microtubules, microtubule-interfering agents and apoptosis. Apoptosis 2003; 8: 413-450.

5. Perez EA. Microtubule inhibitors: Differentiating tubulin-inhibiting agents based on mechanisms of action, clinical activity, and resistance. Mol Cancer Ther 2009; 8: 2086-2095.

6. Gottesman MM. Mechanisms of cancer drug resistance. Annu Rev Med 2002; 53: 615-627.

7. Dumontet C, Sikic BI. Mechanisms of action of and resistance to antitubulin agents: microtubule dynamics, drug transport, and cell death. J Clin Oncol 1999; 17: 1061-1070.

8. Fojo T, Menefee M. Mechanisms of multidrug resistance: the potential role of microtubulestabilizing agents. Ann Oncol 2007; 18(Suppl 5): v3-v8.

9. Kavallaris M. Microtubules and resistance to tubulin-binding agents. Nat Rev Cancer 2010; 10: 194-204.

10. Murray S, Briasoulis E, Linardou H, Bafaloukos D, Papadimitriou C. Taxane resistance in breast cancer: mechanisms, predictive biomarkers and circumvention strategies. Cancer Treat Rev 2012; 38: 890-903.

11. Gelderblom H, Verweij J, Nooter K, Sparreboom A. Cremophor EL: the drawbacks and advantages of vehicle selection for drug formulation. Eur J Cancer 2001; 37: 1590-1598.

12. Koolen SL, Beijnen JH, Schellens JH. Intravenous-to-oral switch in anticancer chemotherapy: a focus on docetaxel and paclitaxel. Clin Pharmacol Ther 2010; 87: 126-129.

13. Haftchenary S, Avadisian M, Gunning PT. Inhibiting aberrant Stat3 function with molecular therapeutics: a progress report. Anticancer Drugs 2011; 22: 115-127.

14. Yin ZJ, Zhang Y, Li Y, Lv T, Liu J, Wang X. Prognostic significance of STAT3 expression and its correlation with chemoresistance of non-small cell lung cancer cells. Acta Histochem 2012; 114: 151-158.

15. Germain D, Frank DA. Targeting the cytoplasmic and nuclear functions of signal transducers and activators of transcription 3 for cancer therapy. Clin Cancer Res 2007; 13: 5665-5669.

16. Aggarwal BB, Kunnumakkara AB, Harikumar KB, Gupta SR, Tharakan ST, Koca C et al. Signal transducer and activator of transcription-3, inflammation, and cancer: how intimate is the relationship? Ann NY Acad Sci 2009; 1171: 59-76.

17. Walker SR, Chaudhury M, Nelson EA, Frank DA. Microtubule-targeted chemotherapeutic agents inhibit signal transducer and activator of transcription 3 (STAT3) signaling. Mol Pharmacol 2010; 78: 903-908.

18. Walker SR, Chaudhury M, Frank DA. STAT3 inhibition by microtubule-targeted drugs: dual molecular effects of chemotherapeutic agents. Mol Cell Pharmacol 2011; 3: 13-19.

19. Seshacharyulu P, Ponnusamy MP, Haridas D, Jain M, Ganti AK, Batra SK. Targeting the EGFR signaling pathway in cancer therapy. Expert Opin Ther Targets 2012; 16: 15-31.

20. Shepherd FA, Rodrigues Pereira J, Ciuleanu T, Tan EH, Hirsh V, Thongprasert S et al. Erlotinib in previously treated non-small-cell lung cancer. N Engl J Med 2005; 353: 123-132.

21. Moore MJ, Goldstein D, Hamm J, Figer A, Hecht JR, Gallinger S et al. Erlotinib plus gemcitabine compared with gemcitabine alone in patients with advanced pancreatic cancer: a phase III trial of the National Cancer Institute of Canada Clinical Trials Group. J Clin Oncol 2007; 25: 1960-1966. 
22. Ghosh G, Lian X, Kron SJ, Palecek SP. Properties of resistant cells generated from lung cancer cell lines treated with EGFR inhibitors. BMC Cancer 2012; 12: $p 95$.

23. Wang M, Zhao J, Zhang LM, Li H, Yu JP, Ren XB et al. Combined Erlotinib and Cetuximab overcome the acquired resistance to epidermal growth factor receptors tyrosine kinase inhibitor in non-small-cell lung cancer. J Cancer Res Clin Oncol 2012; 138 2069-2077.

24. Szakacs G, Jakab K, Antal F, Sarkadi B. Diagnostics of multidrug resistance in cancer. Pathol Oncol Res 1998; 4: 251-257.

25. Stewart ZA, Tang LJ, Pietenpol JA. Increased p53 phosphorylation after microtubule disruption is mediated in a microtubule inhibitor- and cell-specific manner. Oncogene 2001; 20: $113-124$

26. Dumontet C, Jordan MA. Microtubule-binding agents: a dynamic field of cancer therapeutics. Nat Rev Drug Discov 2010; 9: 790-803.

27. Gelderblom H, Verweij J, Nooter K, Sparreboom A. Cremophor EL: the drawbacks and advantages of vehicle selection for drug formulation. Eur J Cancer 2001; 37: 1590-1598.

28. Nieto Montesinos R, Béduneau A, Pellequer Y, Lamprecht A. Delivery of P-glycoprotein substrates using chemosensitizers and nanotechnology for selective and efficient therapeutic outcomes. J Control Release 2012; 161: 50-61.

29. Canitrot $Y$, Lautier D. [Use of rhodamine 123 for the detection of multidrug resistance]. Bull Cancer 1995; 82: 687-697.

30. Shapiro AB, Ling V. The mechanism of ATP-dependent multidrug transport by P-glycoprotein. Acta Physiol Scand Suppl 1998; 643: 227-234.

31. Gavet O, Pines J. Activation of cyclin B1-Cdk1 synchronizes events in the nucleus and the cytoplasm at mitosis. J Cell Biol 2010; 189: 247-259.

32. Coulonval K, Kooken H, Roger PP. Coupling of T161 and T14 phosphorylations protects cyclin B-CDK1 from premature activation. Mol Biol Cell 2011; 22: 3971-3985.

33. Malumbres M. Physiological relevance of cell cycle kinases. Physiol Rev 2011; 91 973-1007.

34. Andrews PD, Knatko E, Moore WJ, Swedlow JR. Mitotic mechanics: the auroras come into view. Curr Opin Cell Biol 2003; 15: 672-683.

35. Lens SM, Voest EE, Medema RH. Shared and separate functions of polo-like kinases and aurora kinases in cancer. Nat Rev Cancer 2010; 10: 825-841.

36. Fan TJ, Han LH, Cong RS, Liang J. Caspase family proteases and apoptosis. Acta Biochim Biophys Sin (Shanghai) 2005; 37: 719-727.
37. Thomas LW, Lam C, Edwards SW. Mcl-1; the molecular regulation of protein function. FEBS Lett 2010; 584: 2981-2989.

38. Aggarwal BB, Sethi G, Ahn KS, Sandur SK, Pandey MK, Kunnumakkara AB et al. Targeting signal-transducer-and-activator-of-transcription-3 for prevention and therapy of cancer: modern target but ancient solution. Ann NY Acad Sci 2006; 1091: 151-169.

39. Walker SR, Chaudhury M, Nelson EA, Frank DA. Microtubule-targeted chemotherapeutic agents inhibit signal transducer and activator of transcription 3 (STAT3) signaling. Mol Pharmacol 2010; 78: 903-908.

40. Liu H, Tekle C, Chen YW, Kristian A, Zhao Y, Zhou M et al. B7-H3 silencing increases paclitaxel sensitivity by abrogating Jak2/Stat3 phosphorylation. Mol Cancer Ther 2011; 10: 960-971.

41. Sangodkar J, Katz S, Melville H, Narla G. Lung adenocarcinoma: lessons in translation from bench to bedside. Mt Sinai J Med 2010; 77: 597-605.

42. Francis $\mathrm{H}$, Solomon B. The current status of targeted therapy for non-small cell lung cancer. Intern Med J 2010; 40: 611-618.

43. Uribe MC, Grier HJ, Parenti LR. Ovarian structure and oogenesis of the oviparous goodeids Crenichthys baileyi (Gilbert, 1893) and Empetrichthys latos Miller, 1948 (teleostei, Cyprinodontiformes). J Morphol 2012; 273: 371-387.

44. Tsai AC, Pan SL, Sun HL, Wang CY, Peng CY, Wang SW et al. CHM-1, a new vascular targeting agent, induces apoptosis of human umbilical vein endothelial cells via p53-mediated death receptor 5 up-regulation. J Biol Chem 2010; 285: 5497-5506.

Cell Death and Disease is an open-access journal published by Nature Publishing Group. This work is licensed under a Creative Commons Attribution 3.0 Unported License. The images or other third party material in this article are included in the article's Creative Commons license, unless indicated otherwise in the credit line; if the material is not included under the Creative Commons license, users will need to obtain permission from the license holder to reproduce the material. To view a copy of this license, visit http://creativecommons.org/licenses/by/3.0/

Supplementary Information accompanies this paper on Cell Death and Disease website (http://www.nature.com/cddis) 